\title{
O CONCF.ITO DE LIBERDADE EM SANTO AGOSTINHO
}

\author{
THE CONCEPT OF FREEDOM ACCORDING TO ST. AUGUSTINE
}

Eduardo Tomasevicius Filho'

\section{Resumo:}

Fstc trabalho examinará a problemática da liberdade como livre-arbitrio em Santo Agostinho e fará uma comparação de suas idéias com a teoria finalista da ação, criada por Hans Welzel no início do século XX.

Palavras-chave: Santo Agostinho. Conceito de liberdade. Livre-arbitrio.

Abstract:

This article will study the problem of freedom as free will according to St. Augustine and will compare his thoughts with the final action's theory, created by Hans Welzel in the beginning of the $20^{\text {th }}$ century.

Keywords: Saint Augustine. Concept of freedom. liree will.

\section{Introdução}

Este trabalho examinará a problemática da liberdade como livre-arbítrio em Santo Agostinho.

A idéia de livre-arbitrio, criada para fundamentar as idéias de mal e pecado, relacionou a liberdade com a vontade humana. Isso foi uma mudança radical em relação pensamento clássico, em que a liberdade era um status e relacionava-se com a política.

Será feita uma apresentação dos antecedentes filosóficos a Santo Agostinho, uma breve exposição e critica de seu pensamento e, ao final, compará-lo com a teoria finalista da ação do Direito Penal, criada na primeira metade do século XX por Hans Welzel.

\section{Antecedentes filosóficos}

Na segunda metade do século IV a.C.. Atenas ficou politicamente subjugada aos macedônios, que formaram um vasto império que compreendia, além da Grécia. o Oriente Médio e Norte da África. Isso possibilitou ao pensamento grego

Bacharel e Doutorando em Direito (ivil pela Faculdade de Direito da I niversidade de São Paulo.

Advogado em Sào Paulo. 
expandir-se para essas regiões. Desse fato surgiu uma nova escola filosófica, o helenismo, que consistiu na universalização da língua e cultura gregas pelo Império macedônio, ao mesmo tempo ım que recebia a influência de novas idéias de outros povos. Surgiram vários centros culturais, como $\mathrm{cm}$ Alexandria, no Egito, cidade em que viviam egipcios, judeus e gregos.

$O$ helenismo foi um reflexo das transformações por que passava o mundo antigo. Enquanto nos tempos de Sócrates. Platão e Aristóteles, a realização do ser humano se dava na pólis, o Império macedônio inseriu o ser humano num novo universo político. De acordo com Mondin (1981. p. 108), ao comentar o contexto do helenismo. diz que o ser humano "(...) não pode atingir a felicidade senão apoiando-se em suas próprias forças e recolhendo-se em si mesmo" As exigências filosólicas desse períudo pediam sobretudo uma norma de vida. o segredo da felicidade, um princípio de conduta que assegure a paz da alma.

O estoicismo foi o principal movimentu fílosófico do helenismo. Esta escola filosófica sustentava que a felicidade estava na virtuosidade, que consistia na disposição interna pela qual a alma estaria em harmonia consigo mesma, vivendo segundo a razão. anulando-se as paixões. Estas últimas, de acordo com os estóicos. seriam cadeias que ligariam a alma ao corpo e impediriam que a alma se ligasse ao Logos.

Quando o mundo antigo passou a ser dominado pelos romanos. surgiu uma nova religião que trazia refrigério para a angústia que tomava conta daquela época: o Cristianismo.

A mensagem de Jesus Cristo fundou uma nova ética e inaugurou uma nova visão sobre Déus e sua relação com a humanidade. Porém, era necessário fundamentar filosoficiamente esta nova religião. Por esse motivo se verifica a importância da tradição filosófica grega - no caso, o helenismo na elaboração de uma teologia cristã.

Clemente de Alexandria (150-215) foi o primeiro pensador cristão a procurar realizar esta sintese entre o C'ristianismo e o helenismo. Para este, a Filosofia tinha um papel propedêutico à fé cristã. Deus teria dado a Lei aos judeus e a Filosofia aos gregos para que pudessem futuramente acreditar na vinda de Cristo. O papel da Filosofia, após à vinda de Cristo, seria o de permitir que os indivíduos pudessem chigar à fé racionalmente.

Outras correntes filosóficas que uniram a tradição filosófica grega com outras tradições religiosas também influenciaram o Cristianismo. São elas o maniqueísmo e o neoplatonismo. 
O maniqueismo teve como fundador Manes, ou Mani, que nasceu na Babilônia no início do século III, e pregou por toda a Ásia, incluindo a Pérsia, Índia e China. O maniqueismo tem muitos elementos do Cristianismo, bem como de outras religiões, como o budismo e, sobretudo, o mazdeísmo. O ponto fundamental do maniqueísmo é o dualismo irredutivel do bem e do mal, da luz e das trevas, de Deus c do Diabo. (Marías, 1966, p. 127)

Plotino (205-270), fundador do neoplatonismo, foi o responsável pela síntese da Filosofia grega com as religiões orientais. Seu pensamento filosófico era voltado para o Uno e as relações dos seres humanos com este Uno. O Uno seria a realidade suprema da qual se originaram todas as outras coisas. As coisas se separaram do Uno por meio da emanação, que consistiu no surgimento a partir de novas entidades, sem que essa realidade suprema tivesse deixado de existir. A primeira emanação foi o Nous (inteligência); do Nous emanaram as almas. Os corpos dão forma a às almas. A matéria seria o grau infimo do ser, ou quase um não-ser. A missão da alma seria restabelecer a unidade original das coisas, reconduzindo-as ao Uno. O retorno da alma ao Uno seria obra da liberdade.

\section{Breve histórico de Santo Agostinho}

Aurelius Augustinus nasceu em 13 de novembro de 354 em Tagasta, província romana da Numídia, região do Norte da África. Era filho de Patrício, pagão, talvez descendente de um antigo legionário romano. de acesa sensualidade, e de Mônica, mulher de fervoroso espirito cristão, e que veio posteriormente a ser canonizada pela Igreja Católica. A vida de Agostinho foi marcada por uma forte tensão entre essa dupla herança de temperamentos paterno e materno. (Rohden, 1991, p. 18).

Iniciou seus estudos em Tagaste e Madaura. Para que pudesse ser eventualmente um professor ou magistrado, seu pai, Patrício sacrificou-se para enviar Agostinho a Cartago.

Agostinho passou sua juventude ligado aos prazeres da carne. A despeito dos esforços de seu pai para que estudasse em Cartago, não gostava de estudar. Nesta cidade, teve relacionamentos amorosos fora dos padrões da época e também um filho, Adeodato, que faleceu na adolescência.

Foi também nessa época que teve contato com a Filosofia, ao ler o Hortênsio, de Cícero. Leu os Evangelhos, mas estes the pareceram pueris. Assim, Agostinho buscou a verdade no maniqueísmo. (Rohden, 1991, p. 63-5). 
Com o falecimento de seu pai, teve que regressar a Tagaste e lá abriu uma escola. Tempos depois, exerceu o cargo de professor de retórica em Cartago. Pelo fato dos alunos não se interessarem pelos estudos - apenas o faziam para cumprir obrigações familiares - decidiu mudar-se para Roma. Enquanto aguardava sua transferência, passou a ler obras de Aristóteles na tradução latina -... Agostinho havia negligenciado os estudos de grego em sua juventude.

Agostinho ficou pouco tempo em Roma. Estava imerso em grandes questões intelectuais. Nesta mesma época, havia abandonado o maniqueísmo e passou a freqüentar a Academia platônica, tendo contato com o neoplatonismo. Logo em seguida transferiu-se para Milão. Conheceu Santo Ambrósio, bispo de Milão, que contribuiu para a sua conversão ao Cristianismo, por volta de 386. (Rohden, 1991, p. 111) Decidiu voltar-se para a religião. Batizou-se na Páscoa do ano seguinte.

Ao regressar a Tagaste, vendeu as propriedades paternas e criou uma comunidade monástica. Pretendia passar a vida inteira estudando racionalmente o Cristianismo. Em 391 tornou-se presbítero em Hipona. Anos depois tornou-se bispo de Hipona.

Agostinho produziu diversas obras, sendo que algumas delas visavam combater determinadas doutrinas, entre elas, os astrólogoas, judeus, maniqueus, priscilanistas, donatistas, pelagianos, arianos e apolinaristas. Suas principais obras são as seguintes: Contra os Acadêmicos (386), Solilóquios (387), Do Livre-Arbitrio (388-395), De Magistro (389), Confissões (400), Espirito e Letra (412), A Cidade de Deus (413426) e Retratações (413-426).

4. Idéias fundamentais sobre o livre-arbítrio

\subsection{A origem do pecado}

O termo "livre-arbítrio" na etimologia latina, significa livre decisão. Na perspectiva inaugurada por Santo Agostinho, a liberdade passou a ser uma opção do ser humano de determinar o seu caminho, cujos parâmetros de escolha estão delimitados por uma ordem exterior. a qual estabelece o "valor" ou o "desvalor" de cada opção.

No pensamento de Santo Agostinho há várias dicotomias que orientam a sua concepção de livre-arbítrio, que podem ser agrupadas em dois grupos opostos, conforme segue no quadro abaixo. Esses conceitos são fundamentais em seu pensamento. porque o livre-arbítrio consiste na opção do ser humano entre buscar o bem (retidão) ou buscar o mal (pecado). 


\begin{tabular}{|c|c|}
\hline Bem & Mal \\
\hline Existência & Ausência \\
\hline Retidão & Pecado \\
\hline Razão & Paixão \\
\hline Felicidade & Infortúnio \\
\hline Lei Eterna & Lei Temporal \\
\hline
\end{tabular}

Quadro 1: Dicotomias no pensamento de Santo Agostinho

Para um cristão, é um dilema saber que Deus, criador de tudo o que existe com perfeição, possa ter criado o mal. São inevitáveis as perguntas: sendo Deus perfeito, como pode existir o mal!? Ou, ainda, se o pecado procede dos seres criados por Deus, como não Lhe atribuir a existência dos pecados? Por isso, Santo Agostinho necessitava de todas as maneiras refutar a origem divina do mal.

Em O Livre-Arbitrio, Santo Agostinho define o mal como sendo a ausência de Deus. (Agostinho, 1995, p. 142-3) Essa ausência é decorrência da opção do ser humano por um caminho que o afaste do bem, uma vez que o mal não pode vir de Deus.

Assim surge a idéia de livre-arbítrio, como aquilo que confere ao ser humano a vontade livre de decidir seguir um ou outro caminho. Logo, a fonte do mal é o próprio ser humano, que, por livre decisão, afasta-se de Deus e. conseqüentemente, cria o mal.

Esta dicotomia entre o bem e o mal preparou o terreno para a formulação de dois conceitos que estruturam a noção de livre-arbítrio: a retidão e o pecado.

A retidão consiste na submissão das paixões à razão. O pecado, por sua vez, é o inverso: consiste na submissão da razão às paixões.

A causa do pecado é a vontade livre decorrente do livre-arbítrio, uma vez que nada força a razão submeter-se às paixões, nem esta à razão. Por isso, só quem tem o livre-arbitrio pode pecar.

Um problema surge: se o livre-arbítrio é a origem do mal no mundo, por que Deus o deu ao ser humano? Ou seja. se não houvesse o livre-arbítrio, não haveria pecado. Não se trata da colocação inicial de Santo Agostinho, que procurava afastar que Deus pudesse ter criado o mal.

Em resposta a essa indagação, Santo Agostinho diz que o livre-arbítrio é um bem e um dom de Deus. Ele dá o exemplo da visão, que é um dom de Deus, que permite ao ser humano enxergar. Não é porque se pode pecar por meio dos olhos (cobiça) que Deus não deveria ter dado a visão. Por causa do livre-arbítrio, o insensato, 
isto é, o ser humano cuja mente é dominada pelas paixões, pode, com justiça, ser castigido, por ter feito um mau uso do seu livre-arbítrio. (Agostinho, 1995, p. 75) Sem o livre-arbítrio, não existiria justiça nem a retidão. De nada adiantaria elogiar os retos e condenar os maus. O problema do livre-arbítrio está em fazer mau uso deste, e não, de condenar Deus por tê-lo concedido ao ser humano. Em tese, para Santo Agostinho, o ser humano tem a possibilidade de não-pecar e o poder de decidir se quer ou não-pecar. É nesse sentido que deve se compreender o livre-arbítrio como causa do pecado.

Estabelecido que a causa do pecado era o livre-arbítrio, surge a necessidade de saber o que ura ou-não era pecado. Para tanto, Santo Agostinho lança mais uma dicotomia: a lei eterna e a lei temporal.

A lei eterna é a razão suprema de tudo (Nous), à qual é preciso obedecer sempre e em virtude da qual os seres humanos bons merecem uma vida feliz (felicidade), e os maus, uma vida infeliz (infortúnio). (Agostinho, 1995, p. 41) Ela ordena ao ser humano que se desapegue do amor pelas coisas temporais e que se volte para as coisas eternas, que conduzem à beatitude. Por ser a razão suprema, a lei eterna $\mathfrak{e}$ a Verdade e a verdadeira liberdade consiste em seguir a lei eterna. A Verdade está na mente humana, isto $\dot{e}$, na razão, já que é por meio da razão que se descobre a Verdade. Santo Agostinho diz: "A nossa liberdade consiste em estar submetido à Verdade. Essa Verdade é o nosso Deus mesmo, o qual nos liberta da morte, isto é, da condição do pecado" o que lembra a frase de Cristo: "Conhecereis a Verdade, e a Verdade vos libertará"

Já a lei temporal é aquela que pode ser alterada com o passar do tempo e que protege o ser humano em relação às coisas temporais (vida, integridade fisica, força. beleza), a fim de salvaguardar a paz e a ordem na sociedade. (Agostinho, 1995, p. 65) O castigo da lei temporal consiste em interditar e privar os seres humanos das coisas temporais. Ela não pune o apego demasiado a essas coisas temporais; apenas pune quem os subtrai injustamente de outrem.

Quando questionado sobre os impulsos que levam o ser humano a agir diferentemente do que gostaria de agir. Santo Agostinho sustenta que, embora o ser humano seja livre para pecar ou ter uma vida reta, essa "necessidade"de pecar vem do hábito. Diz o seguinte (Agostinho. 1996, p. 209)

$\mathrm{O}$ inimigo dominava o meu querer, e dele me forjava uma cadeia com que me apertava. Ora, a luxúria provém da vontade perversa; enquanto se serve a luxúria, contrai-se o hábito; e, se não se resiste a um hábito, origina-se uma necessidade. Era assim que, por uma espécie de anéis entrelaçados - por isso lhes chamei cadeia - me segurava cm dura escravidão. 
Santo Agostinho distingue, pois, o conceito de liberdade do conceito de livre-arbítrio. A liberdade "liberta", no sentido de que o ser humano se vê afastado do pecado, vivendo na graça divina, em oposição à escravidão, que consiste no atendimento das paixões. Já o livre-arbítrio é liberdade por excelência, porque é do seu exercício que o ser humano pode escolher em seguir uma vida reta ou pecaminosa.

\subsection{A presciência $X$ livre-arbitrio}

Se era complexo conseguir conciliar os atributos divinos da perfeição e onipresença em face da existência do pecado, questão mais complexa Santo Agostinho teve que enfrentar em relação à onisciência de Deus: o problema da presciência em face do livre-arbitrio do ser humano.

O ser humano tem uma vida reta ou pecaminosa segundo a sua vontade livre. Não se trata, pois, de uma necessidade natural. isto é. da impossibilidade de pecar ou não pecar. Por isso, só faria sentido falar em livre-arbítrio quando coubesse única e exclusivamente ao ser humano decidir, a cada momento, que caminho tomar. Seria totalmente aleatório e imprevisível saber se o ser humano vai ou não-pecar. E se o livrearbítrio é um dom de Deus, nem Ele pode interferir nessa escolha. O máximu que pode fazer é esperar que o ser humano $\mathrm{O}$ busque.

Por outro lado. a onisciência divina significa que Ele sabe de tudo que ocorreu no passado, neste exato instante e no futuro. Disso surge o problema: para que Deus saiba o futuro. Ele necessariamente sabe se o ser humano vai ou não-pecar a cada momento. A presciência implica a predestinação. Neste caso. Deus escolhe primeiro os seus eleitos e depois lhes dá us meios para corresponderem a essa eleição.

Nos capítulos IX a XI da Cidade de Deus, Santo Agostinho comenta uma obra de Cícero, chamada Subre a Adivinhação, por meio da qual ele discute a validade ou não da ciência do futuro, e a presciência de Deus e do ser humano. Não seria possível a presciência do futuro, porque haveria um dilema: ou se nega a existência da fatalidade ou se nega a existência da vontade livre. (Agostinho, 1990, p. 201) Santo Agostinho, agora já como um bispo, procurará justificar a existência de Deus e afirmar a inexistência de contradição entre a onisciência e a presciência do futuro.

Santo Agostinho amplia a idéia de causa para justificar a existència do livre-arbítrio. Afirma que não existe apenas a causa eficiente dos gregos relação de causalidade. Existem, ainda, outras causas, como a causa fortuita e a causa voluntária. A vontade divina, dos anjos e demônios, e a dos seres humanos, seriam causas voluntárias. 
Para ele, a vontade é a causa da ação humana e Deus conhece todas as causas, isto é, conhece previamente a vontade humana. (Agostinho, 1990, p. 202)

Assim, Deus é capaz de prever a vontade humana, porque prever não significa forçar o ser humano a ter uma determinada vontade em detrimento de outra.

A saída para esse dilema está quando Santo Agostinho afirma que a onisciência de Deus significa que Deus não pode se enganar. Logo, Deus é capaz de saber se o ser humano realmente pecou ou-não. porque Ele sabe aquilo que depende da vontade do ser humano. (Agostinho, 1990, p. 205)

\section{Problemática}

O conceito de livre-arbitrio agostiniano foi uma revolução em relação ao conceito de liberdade da Antigüidade clássica.

Como acentua Arendt (1972, p. 204), "para a história do problema da liberdade, a tradição cristã tornou-se de fato o fator decisivo. Quase que automaticamente equacionamos liberdade com livre-arbítrio"

Em Atenas a liberdade tinha uma extensão positiva c estava relacionada à participação ativa e coletiva do poder político. Significava o indivíduo que, na pólis, pertencia ao grupo social e não estava subordinado a ninguém.

Este caráter da liberdade como pertinência ao grupo social fazia com que esta fosse considerada um status. É livre quem pertence ao grupo social. Quem não era livre, era considerado bárbaro. Em relação à não-subordinação a ninguém, isso significava participar das deliberações em praça pública sobre a guerra e a paz, na votação das leis, participar dos julgamentos, e no exame das contas públicas e na gestão dos magistrados. (Constant, 1985, p. 11)

Como aponta Ferraz Jr (2002, p. 77)

o uso do termo liberdade, entre os gregos, tem, portanto, uma conotação fortemente política e jurídica (liberdade/isonomia), sem ligação, porém, com as noções subjetivas de ato voluntário em oposição ao involuntário. Não que os gregos desconhecessem essa oposição, mas a ela não conferiram o atributo de liberdade.

O Cristianismo, por seu turno, oferecia o Reino de Deus, no qual todos eram livres. Ista idéia de universalização da liberdade se relaciona com a própria mensagem das Escrituras Sagradas, de que Jesus Cristo veio para constituir uma nova 
aliança entre Deus e a humanidade, extensiva a todo e qualquer ser humano, e não a um povo determinado. Daí a liberdade não poder ser um status de um grupo social.

Santo Agostinho contribuiu para a justificação filosófica deste conceito cristão de liberdade, invertendo filosoficamente o seu locus. Ao contrário dos gregos, Santo Agostinho fundou-a na vontade interior do ser humano. Todos os seres humanos são livres na esfera intima para decidirem sobre o que fazer em cada momento de suas vidas: poderiam optar por uma vida reta, buscando Deus, ou por uma vida pecaminosa, afastando-se de Deus. Essa "igualdade de condições" atingia a todos os indivíduos. Ainda que o ser humano fosse um escravo (não ter a liberdade exterior), ainda assim era livre no seu interior. (Arendt, 1972, p. 193) Para os gregos, só era possível querer aquilo que fosse possível; agora, pode-se querer, ainda que não possa. (Ferraz Jr, 2002, p. 88)

Além disso, Santo Agostinho teve que encontrar uma saída para a existência do mal no mundo, uma vez que Deus é perfeito e poderia não ter criado o mal. Ele afastou a origem divina do mal e fez isso por meio do livre-arbítrio. Nesse ponto, houve um afastamento do maniqueísmo. ao falar que o mal é a ausência de Deus, e não uma realidade ontológica, e uma aproximação do neoplatonismo, ao dizer que o melhor é voltar-se para Deus (o Uno). O problema do mal, porém, não é resolvido, porque, se Deus não tivesse dado o livre-arbítrio ao ser humano, não haveria o pecado e, por conseguinte, o mal. Esse problema deve-se ao fato de que o cristianismo, por ter herdado a idéia de criação do nada (ex nihilo), teve que enfrentar a necessidade de justificação da existência das coisas, uma vez que elas poderiam ser ou não-ser de outra forma. (Marías, 1966, p. 119)

Modernamente, Schopenhauer (p. 160) define livre-arbítrio como sendo a liberdade de indiferença, na qual a vontade livre do ser humano não é determinada por qualquer razão ou motivo. Mais adiante, nega a existência do livre-arbítrio, porque todos os motivos do ser humano têm uma causa, relacionada ao caráter de cada um.

Embora Santo Agostinho afirmasse a existência do livre-arbítrio, a idéia de que o livre-arbitrio não era uma livre decisão imotivada já estava presente em seu pensamento, ao ter afirmado que os hábitos bons e ruins condicionam as decisões do ser humano de buscar uma vida reta ou pecaminosa. A crítica de Schopenhauer nesse aspecto não é suficientemente contundente para afastar a concepção agostiniana de livrearbítrio.

Uma característica complementar à idéia de livre-arbitrio é a existência de uma ordem superior denominada lei eterna - a qual prescreve o que deve ser feito pelo ser humano e, portanto, estabelecerá em cada caso se houve um bom uso ou um abuso do livre-arbitrio, porquanto o mal ter a sua causa no abuso do livre-arbítrio. Se não 
houvesse essa ordem, o livre-arbitrio perderia a sua razão de ser. dentro do pensamento de Santo Agostinho, já que este foi dado por Deus, como uma forma de justificar a existência do mal em contraposição à perleição divina.

Santo Agostinho usa a justiça como uma conseqüência do pecado, o que justifica a responsabilização do ser humano pelos abusos que cometeu no exercício de seu livre-arbitrio. Esta responsabilização consiste em suportar as conseqüências que desse abuso seguem, em face da lei eterna. $\Lambda$ justiça, no sentido de dar a cada um o que é seu, tem uma laceta divina, e ser justo é uma das qualidades de Deus. Ele pune quem não segue us seus preceitos. Caso não fosse assim, de nada adiantaria fazer um bom uso do livre-arbitrio e a lei eterna, que prescreve ser melhor a retidão em detrimento do pecado, ficaria invertida, porque a recompensa dos maus seria a própria ausência de punição. No entanto. Santo Agostinho questiona a justiça divina em A Cidade de Deus, pois na queda do Império romano do Ocidente. houve quem atribuisse essa queda ao Cristianismo. Como o Império romano havia adotado o cristianismo como religião oficial, muitos dos males por que passaram, não deveriam ter acontecido!

Talvez o único ponto que Santo Agostinho não tenha conseguido resolver em definitivo é o dilema entre o livre-arbítrio e a predestinação. O livre-arbítrio agostiniano não admite, em tese, que a razão prepondere sobre as paixões e vice-versa. Em face dos problemas ou das tentações - o ser humano é livre para decidir o que fazer nessa situação e pode resistir ao pecado por livre e espontânea vuntade. Dessa forma, o comportamento humano seria verdadeiramente imprevisível e prevê-lo seria mera loteria. Se isso fosse possível - inclusive para Deus não haveria liberdade. porque as opções já teriam sido previamente decididas. Mesmo ao justificar que Deus soubesse que uma determinada causa do comportamento humano ficaria a cargo da vontade humana, ainda assim permaneceria o dilema. porque apenas estaria estabelecida u espaço de "autonomia" da vontade: mas ainda assim, dentro desse espaço de "autonomia" nem Deus teria como saber qual seria a vontade humana.

\section{Repercussões do livre-arbitrio no pensamento contemporâneo}

Se a idéia de liberdade com fundamento na vontade humana surgiu com Santo Agostinho, talvez seu ocaso seja na fundamentação da teoria finalista da ação, construída na primeira metade do século $X X$, que teve como precursor o filósofo e jurista alemão Hans Welzel. O Código Penal brasileiro procurou adotá-la na reforma por que passou em 1984. 
Como explica Welzel (200l, p. 28), "a espinha dorsal da ação finalista é a vontade, consciente do fim, reitora do acontecer causal. Sem ela, a ação seria um processo causal cego"

Para a teoria finalista, a ação é o exercício de uma atividade final, que se baseia no fato de que o ser humano pode prever, dentro de certos limites. as possíveis conseqüências de sua conduta e, por isso mesmo, é capaz de autodeterminar-se e escolher qual caminho seguir. Daí a importância de levar em consideração qual era a sua vontade no momento da realização da ação.

Esta teoria sucedeu a teoria da ação causal, para a qual o que importa. no julgamento da conduta criminosa pelo juiz, é saber se o fato foi ou-não provocado pela vontade, independentemente do que o agente tenha querido.

No momento de aplicação da pena, o juiz faz a análise da conduta do indivíduo, levando em conta se este realizou ou não a conduta prevista em lei como criminosa (tipicidade), qual a intenção do agente (se agiu com dolo ou com culpa), e se esta conduta era contra o ordenamento jurídico (antijuridicidade) ou permitida pelo ordenamento jurídico (legítima defesa, estado de necessidade, estrito cumprimento do dever legal). Porém, para a teoria finalista, é preciso examinar se essa conduta do indivíduo é reprovável (culpável), por não haver atuado corretamente. apesar de ter podido agir de outra maneira.

Assim, a culpabilidade é inserida por Welzel como um elemento do crime, ao lado da tipicidade e da antijuridicidade, e significa a falha de uma decisão conforme a finalidade em um sujeito responsável, e não é um ato de livre autodeterminação. Em outras palavras, significa a reprovabilidade da resolução da vontade. (Welzel, 2001, p. 88)

A teoria finalista da ação em muito se assemelha com o livre-arbitrio agostiniano. Aliás, um dos pressupostos existenciais da reprovabilidade da culpabilidade é o livre-arbítrio do ser humano (Welzel, 2001, p. 93).

O primeiro ponto de contato entre ambos os pensamentos é que, tanto em Santo Agostinho, quanto em Welzel, a vontade é o fundamento da punição do indivíduo. Do contrário. seria injusto punir um indivíduo que não tinha como determinar-se, agir de uma determinada maneira.

O segundo ponto de contato é que a culpabilidade não significa uma livre decisão em favor do mal, mas o individuo ficar preso pelos impulsos, quando o indivíduo podia se autodeterminar conforme os fins. Está presente a idéia de responsabilização do indivíduo por ter feito um mau uso de sua liberdade, ao ter optado praticar uma conduta "má" E no momento de responsabilizar o indivíduo, o juiz mede o 
quanto o indivíduo usou mal o seu livre-arbítrio. Logo, para ambos, o mal. decorrente da existência do livre-arbítrio, não tem uma existência ontológica, mas adquire um significado de privação. de falha, do exercício de uma vontade livre, não no sentido de escolher entre o bem e o mal, mas de poder escolher fazer o bem.

Ademais, a ordem que estabelece o certo e o errado para Santo Agostinho - a lei eterna é uma ordem externa ao indivíduo, embora seja descoberta dentro de si. Como visto acima, a Verdade estaria na mente humana. A lei eterna estabelece o caminho desejável que o ser humano deve trilhar, e fica a cargo do livre-arbítrio do ser humano trilhá-lo ou não. No direito penal ocorre o mesmo: o indivíduo tem diante de si uma ordem externa (o Código Penal), que estabelece quais condutas não são permitidas, e o livre-arbítrio determina se o indivíduo praticará ou-não uma conduta criminosa prevista no Código Penal.

A única diferença entre o pensamento de Santo Agostinho e a teoria finalista é que, para este, é necessária a manifestação desta vontade através da conduta. Isso porque o fundamento do crime está na existência de um desvalor da conduta e um desvalor do resultado (dano ou perigo de dano), e, portanto, o Direito Penal não pune a mera intenção. Já no pensamento de Santo Agostinho, a intenção pode ser punida, porque Deus é onisciente.

\section{Conclusão}

Santo Agostinho introduziu na história da liberdade a idéia de livrearbitrio. Isso marcou profundamente a compreensão da liberdade. Essa concepção de liberdade foi uma resposta à necessidade de solucionarem-se dilemas relativos à teologia cristã.

O livre-arbítrio está em ter sido a primeira idéia universal de liberdade, fundando-a na vontade do ser humano. Dessa maneira, todo e qualquer ser humano poderia ser livre em qualquer condição, e não apenas um determinado grupo social.

A importância de Santo Agostinho na Filosofia ocidental está no fato de ter renovado o pensamento helenístico, que estava se esgotando com o declínio do Império romano do Ocidente, embora estivesse buscando uma fundamentação filosófica para determinados atributos de Deus, como a perfeição, a onipotência, a onisciência e a onipresença, à existência do mal no mundo e o destino do ser humano. A necessidade de respostas fez surgir a Patrística, que foi uma síntese entre a tradição filosófica grega e as Escrituras Sagradas. 
Dessa maneira. Santo Agostinho também contribuiu para a influência do pensamento helenístico na teologia cristã. As noções de bem e mal, retidão e pecado, como decorrência do livre-arbítrio, contribuíram para a consolidação da idéia de responsabilidade do ser humano por seus atos e sua punição, quando praticados em transgressão à lei. Essa noção permanece até os nossos dias na teoria finalista da ação do Direito Penal.

São Paulo, fevereiro de 2006.

\section{Referências}

AGOSTINHO, Santo. 4 Cidade de Deus: (contra os pagãos). Tradução Oscar Paes Leme. 4. ed., pt. J. Petrópolis: Editora Vozes, e São Paulo: Fundação Agostiniana Brasileira, 1990.

Confissões. Tradução J. Oliveira Santos, S.J., e A. Ambrósio de Pina, S.J. São Paulo: Nova Cultural, 1996. (Coleção Os Pensadores).

O Livre-Arbitrio. 3. ed. Tradução Nair de Assis Oliveira. São Paulo: Paulus, 1995.

ARENDT, Hannah. Qu' é liberdade? In: ENTRE o Passado e o Futuro. 2. ed. São Paulo: Perspectiva, 1972.

CONSTANT. Benjamin. Da liberdade dos antigos comparada à dos modernos. Tradução Loura Silveira. In: FILOSOFIA Política 2. Porto Alegre: LP\&M Editores, 1985. p. 9-25.

FERRAZ JÚNIOR, Tércio Sampaio. Estudos de Filosofia do Direito: Reflexões sobre o Poder, a Liberdade, a Justiça e o Direito. São Paulo: Atlas, 2002.

MARIAS, Julian. História da Filosofia. Porto: Fdições Sousa \& Almeida, 1966.

MONDIN, Battista. Curso de Filosofiu. Tradução Benôni Lemos. São Paulo: Edições Paulinas. 1981. v. 1.

RUHDEN, Huberto. Agostinho: um drama de humana miséria e divina miscricórdia. São Paulo: Editora Martin Claret, 1991.

SCHOPENHAUER, Arthur. O Livre-Arbitrio. Belo Horizonte: Editora Novo Horizonte, s.d. (Coleção Os Grandes Clássicos da Literatura $\quad$ v. III)

WELZEL, Hans. O Novo Sistema Juridico-Penal: uma introdução à doutrina da ação finalista. Tradução do Espanhol por Luiz Regis Prado. São Paulo: Revista dos Tribunais. 2001. 